\title{
Lysosomal Cystine Transport in Cystinosis Variants and their Parents
}

\author{
WILLIAM A. GAHL AND FRANK TIETZE \\ Section on Human Biochemical Genetics, Human Genetics Branch, NICHD and Laboratory of Molecular and \\ Cellular Biology, NIDDKD, National Institutes of Health, Bethesda, Maryland 20892
}

\begin{abstract}
Children with nephropathic cystinosis store 50 to 100 times normal amounts of free cystine in many cells and display negligible lysosomal cystine transport in their leucocytes and cultured fibroblasts. A patient with intermediate (adolescent) cystinosis exhibited a similar deficiency of egress out of fibroblast lysosome-rich granular fractions. Another individual with benign (adult) cystinosis accumulated only $2.85 \mathrm{nmol} 1 / 2$ cystine/mg leucocyte protein, or $\mathbf{2 0 - 5 0 \%}$ of the amount stored in nephropathic cystinosis leucocytes. His leucocyte granular fractions also displayed substantial residual cystine-carrying capacity, as determined by measurement of lysosomal cystine countertransport. We conclude that the variant forms of cystinosis represent a continuum of lysosomal cystine storage, with the varied clinical presentation depending on the amount of residual cystine-carrying capacity, genetic predispositions, and differential tissue susceptibilities. (Pediatr Res 21: 193-196, 1987)
\end{abstract}

Infantile nephropathic cystinosis is a lysosomal storage disorder inherited in an autosomal recessive fashion and characterized by renal Fanconi syndrome in the 1st yr of life with subsequent growth retardation, corneal cystine crystals, and glomerular dysfunction requiring renal transplantation $(1-3)$. In many tissues of cystinosis patients, the disulfide amino acid, cystine, accumulates to such high levels within cellular lysosomes that crystals form. The disorder results from impaired transport of cystine out of lysosomes into the cytoplasm (4-7), where it would normally be reduced to the free thiol, cysteine.

Three varieties of cystinosis have been described. The most common is classical nephropathic cystinosis with onset in infancy and inexorable progression to renal failure in the first decade of life (1-3). In contrast, patients with intermediate (adolescent) cystinosis do not manifest kidney disease until after infancy and have a variable rate of progression to renal demise (8-12). Benign (adult) cystinosis patients have no renal disease at all and live normally as adults except for their corneal crystals (13-18). Intermediate and benign variants of cystinosis have been described in fewer than 20 kindreds.

In addition to their milder disease compared with classical infantile cystinosis patients, individuals with cystinosis variants store lesser amounts of cystine within their cells $(1,2,8,16)$. We determined whether, like nephropathic cystinosis patients, these individuals had impaired lysosomal cystine transport and, if so, to what extent. Two methods of assessing cystine transport were employed, namely, measurements of cystine egress velocity (5) and lysosomal cystine counter-transport or uptake (7). The tech-

Received August 4. 1986: accepted October 1, 1986.

Correspondence Dr. W. A. Gahl, Section on Human Biochemical Genetics, Building 10. Room 10N/318, NICHD, NIH, Bethesda, MD 20892. niques were applied to cells from patients with intermediate and benign cystinosis.

\section{CASE REPORTS}

Patient 1. This boy, patient 2 of a previous report (12), was noted to have corneal opacities at age $5 \mathrm{yr}$, when growth, urinalysis, and creatinine clearance $\left(105 \mathrm{ml} / \mathrm{min} / 1.73 \mathrm{~m}^{2}\right)$ were normal. By age $13 \mathrm{yr}$, serum creatinine was $2.2 \mathrm{mg} / \mathrm{dl}$ and $24-\mathrm{hr}$ urine protein excretion was $3.0 \mathrm{~g}$, prompting a change in the original diagnosis from benign to intermediate cystinosis. A renal allograft was performed at age $14 \mathrm{yr}$. The patient's leucocyte cystine level was $4.4 \mathrm{nmol} 1 / 2$ cystine/mg protein; the father's level was $0.45 \mathrm{nmol} 1 / 2$ cystine/mg protein (12).

Patient 2. A 14-yr-old boy was evaluated at age $6 \%$ yr due to a finding of corneal crystals on routine ophthalmologic examination. Growth was normal, serum creatinine was $0.7 \mathrm{mg} / \mathrm{dl}$, serum electrolytes and urinalysis were normal, bone age was 6$7 \mathrm{yr}$, and there was no evidence of rickets. Crystals were seen in a bone marrow biopsy but not in a renal biopsy which had been fixed in absolute ethanol. A diagnosis of benign cystinosis was made.

By age $14 \% 12 \mathrm{yr}$, the patient was $166 \mathrm{~cm}$ tall $(50 \%)$ and weighed $73 \mathrm{~kg}(90 \%)$. Electrolytes were normal, blood urea nitrogen was $15 \mathrm{mg} / \mathrm{dl}$, serum creatinine was $1.0 \mathrm{mg} / \mathrm{dl}$ with a creatinine clearance of $81 \mathrm{ml} / \mathrm{min}$ (lab normal, $60-90 \mathrm{ml} / \mathrm{min}$ ), urinalysis was normal with urine osmolalities of 410 and $815 \mathrm{mOsmol} /$ liter, undetectable urine protein, and a normal fractional excretion of phosphate $(0.20)$. Bone age was 14 yr. Slit lamp examination revealed crystals in the anterior two-thirds of the corneal stroma. Retinal and skin pigmentation was normal.

\section{METHODS}

The fibroblasts of patient 1 (GM379) and his father (GM906) were obtained from the Human Genetic Mutant Cell Repository (Camden, $\mathrm{NJ}$ ) and grown in minimal essential medium supplemented with $10 \%$ fetal calf serum, glutamine, and nonessential amino acids (19). Polymorphonuclear leucocytes from patient 2 were prepared by dextran sedimentation of heparinized blood and hypotonic lysis of erythrocytes.

Cystine egress from leucocyte $(4,5)$ or fibroblast (19) granular fractions was measured as described. Whole cells were exposed to $0.5 \mathrm{mM}$ (fibroblasts) or $1.0 \mathrm{mM}$ (leucocytes) cystine dimethylester, washed in Hanks' balanced salt solution for $30 \mathrm{~min}$ at $37^{\circ} \mathrm{C}$, and submitted to 30 psi nitrogen cavitation for $10 \mathrm{~min}$ (fibroblasts) or to limited sonication for $10 \mathrm{~s}$ (leucocytes). The cell homogenate was centrifuged at $1000 \times g$ for $5 \mathrm{~min}$ and the supernatant centrifuged at $17000 \times g$ for $10 \mathrm{~min}$. The pellet, a lysosome-rich granular fraction, was placed in $0.25 \mathrm{M}$ sucrose (0.4 M for fibroblasts), $10 \mathrm{mM}$ Hepes, $\mathrm{pH} 7.0$, at $37^{\circ} \mathrm{C}$. At zero time and after 30 or $40 \mathrm{~min}, 1.0-\mathrm{ml}$ aliquots were centrifuged and supernatants and pellets were assayed for cystine and hexosaminidase activity. The amount of cystine appearing in the 
supernatant per min, corrected for lysosomal rupture by the percentage of soluble (supernatant) hexosaminidase activity, gave a measure of lysosomal cystine egress (5).

Cystine counter-transport, not demonstrable in fibroblast granular fractions (19), was measured in polymorphonuclear leucocytes as described (7). Granular fractions, loaded with nonradioactive cystine, were exposed to tracer amounts $(7.5 \mu \mathrm{M})$ of $\left[{ }^{3} \mathrm{H}\right]$ cystine (Amersham, Arlington Heights, IL, final specific radioactivity $875 \mathrm{mCi} / \mathrm{mmol}$ ) in sucrose-Hepes buffer containing $1 \mathrm{mM} \mathrm{N}$-ethyl-maleimide. After 0 and $60 \mathrm{~min}$ at $37^{\circ} \mathrm{C}, 1.0-\mathrm{ml}$ aliquots were removed and centrifuged at $17000 \times g$ for $10 \mathrm{~min}$. The resulting pellets were washed thoroughly of residual $\left[{ }^{3} \mathrm{H}\right]$ cystine, once by resuspension with a pasteur pipet, and once by resuspension using a glass pestle. The final washed pellets were suspended in $1.0 \mathrm{ml}$ of water, sonicated, and assayed for radioactivity and hexosaminidase activity. $\left[{ }^{3} \mathrm{H}\right]$ Cystine uptake after $60 \mathrm{~min}$ in the cystine-loaded granular fractions was compared with that in granular fractions not preloaded with nonradioactive cystine. The difference, which constitutes cystine counter-transport and confirms a carrier-mediated process (21), was expressed as pmol $\left[{ }^{3} \mathrm{H}\right]$ cystine uptake/min/U of hexosaminidase.

One $U$ of hexosaminidase hydrolyzed $1 \mathrm{nmol}$ of 4-methylumbelliferyl-2-acetamido-2 deoxy- $\beta$-D-glucopyranoside substrate per min at $37^{\circ} \mathrm{C}$ under conditions previously described $(4,5)$. Cystine was assayed by the cystine binding protein method (22), and protein was assayed by the method of Lowry et al. (23).

\section{RESULTS}

Patient 1 was considered to have the intermediate or adolescent variant of cystinosis. His cultured fibroblasts stored $14.0 \mathrm{nmol}$ $1 / 2$ cystine/mg protein, a level typical of infantile nephropathic cystinosis fibroblasts (16). The velocity of granular fraction cystine egress was negligible, whether or not the cellular lysosomes were loaded with cystine, and clearly fell within the range for patients with nephropathic cystinosis (Table 1). Fibroblasts from the patient's father stored above normal amounts of cystine, consistent with published values for individuals heterozygous for infantile nephropathic cystinosis (16). Despite this mild increase in endogenous cystine content, the velocity of cystine egress was entirely normal (Table 1).

Patient 2 was considered to have benign or adult cystinosis. His endogenous polymorphonuclear leucocyte cystine content (2.85 nmol $1 / 2$ cystine/mg protein) (Table 2) was lower than reported for infantile nephropathic cystinosis, 4 to $14 \mathrm{nmol} 1 / 2$ cystine/mg protein (16). When tested on two separate occasions, leucocyte granular fractions from this patient displayed 9 and $29 \%$ of the normal amount of cystine countertransport (Table 2 ), well above the range for nephropathic cystinosis $(0-5 \%$ of normal). This indicated a substantial but not complete deficiency of lysosomal cystine carrier function in patient 2 . The patient's parents each exhibited elevated endogenous leucocyte cystine values and reduced lysosomal cystine counter-transport (Table 2). However, both the father and the mother had more than the average expected $50 \%$ of normal carrier function (24), i.e. approximately 67 and $68 \%$, respectively.

Cystine egress from the patient's leucocyte lysosomes was negligible, with no decrement in granular fraction cystine after 40 min (data not shown).

\section{DISCUSSION}

Patients with classical nephropathic (infantile) cystinosis have renal tubular Fanconi syndrome at 6 to 18 months of age, with renal failure requiring transplantation by $10 \mathrm{yr}$ of age. Growth retardation, hypophosphatemic rickets, chronic acidosis, and acute dehydration accompany the Fanconi syndrome. A retinopathy characterized by depigmented retinal epithelium is usually present at the time of diagnosis, and photophobia progresses in severity. Among Caucasians, skin pigmentation is noticeably decreased. Cystine crystals are abundant within the kidney, bone marrow, cornea, conjunctiva, intestine, liver, macrophage, and lymph node cells $(1-3)$.

Intermediate (adolescent) cystinosis is diagnosed between 18 months and $17 \mathrm{yr}$ of age and represents a milder disorder than infantile cystinosis (8-12). Renal glomerular dysfunction clearly occurs, but with decreased severity and a slower rate of progression. Tubular reabsorption deficits do not appear as early or as complete as in infantile cystinosis, but even the original adolescent cystinosis patient described by Goldman et al. (8) had polyuria in infancy. Growth retardation, decreased skin pigmentation, retinopathy, and photophobia are variable in appearance. Typical cystine crystals are observed in the cornea, conjunctiva, bone marrow, and, when sought for, in the kidney (11).

Ophthalmologists generally diagnose benign (adult) cystinosis on the basis of corneal crystals noted incidentally on examination (13-18). These patients have no renal disease or retinopathy and exhibit normal growth and skin pigmentation. Cystine crystals appear in the cornea, bone marrow, and certain leucocytes, but not in the kidney $(13,15,18)$. It may be difficult to distinguish benign from intermediate cystinosis on clinical grounds early in life. Two patients (including patient 1 described herein) were diagnosed as having benign cystinosis at ages 7 and 5 yr based on their entirely normal renal function and growth. However, by ages 15 and $14 \mathrm{yr}$, the patients were uremic and required renal transplantation (12).

What biochemical findings distinguish the three established types of cystinosis? Compared with nephropathic cystinosis fi-

Table 1. Cystine egress from fibroblast granular fractions of patient with late-onset cystinosis and his father*

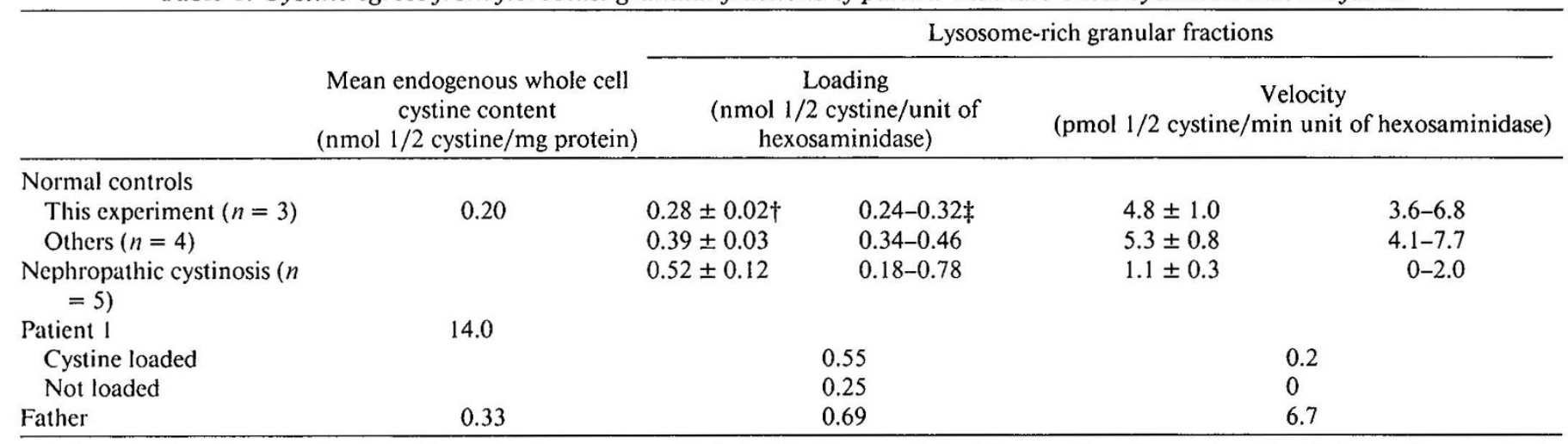

* Granular fractions were loaded with cystine by exposure of whole fibroblasts to $0.5 \mathrm{mM}$ nonradioactive cystine dimethylester. Egress velocity was determined after incubation at $37^{\circ} \mathrm{C}$ for $30 \mathrm{~min}$.

$\uparrow$ Mean \pm SEM.

$\ddagger$ Range. 
Table 2. Cystine counter-transport in leucocyte granular fractions from patient with benign cystinosis and his parents*

\begin{tabular}{lccc}
\hline & $\begin{array}{c}\text { Endogenous whole cell cystine } \\
\text { content } \\
\text { (nmol l/2 cystine/mg protein })\end{array}$ & \multicolumn{2}{c}{ Granular fraction $\left[{ }^{3} \mathrm{H}\right]$ cystine uptake } \\
\cline { 3 - 4 } & $0.17,0.12,0.20$ & $5.0,6.2,5.5$ & 100 \\
Normal controls $(n=3)$ & $0.44 \dagger$ & 0.2 & 4 \\
Nephropathic cystinosis control & & $0-0.3 \ddagger$ & $0-5$ \\
Previous cystinosis controls $(n$ & & & \\
$\quad=6)$ & 2.85 & $0.5,1.6$ & 9,29 \\
Patient 2 & 0.52 & $3.4,4.1$ & 61,73 \\
Father & 0.32 & $3.7,3.9$ & 66,70 \\
Mother & & & \\
\hline
\end{tabular}

* Lysosomal-rich granular fractions, loaded with nonradioactive cystine to at least $5 \mathrm{nmol} 1 / 2$ cystine/U of hexosaminidase, were placed in sucrose-Hepes media containing $7.5 \mu \mathrm{M}\left[{ }^{3} \mathrm{H}\right]$ cystine. After $1 \mathrm{~h}$ at $37^{\circ} \mathrm{C}$, radioactivity taken up was measured and converted to $\mathrm{p}$ moles using the known specific radioactivity of $\left[{ }^{3} \mathrm{H}\right]$ cystine.

$\dagger$ This patient was receiving cysteamine. Untreated levels are $4-14 \mathrm{nmol} 1 / 2 \mathrm{cystine} / \mathrm{mg}$ protein (16).

$\$$ Mean \pm SEM, $0.11 \pm 0.05$.

broblasts and leucocytes, which contain 4 to $14 \mathrm{nmol} \mathrm{1/2} \mathrm{cystine/}$ mg protein (16), benign and intermediate cells generally store less cystine, with overlap between the benign $(1-5 \mathrm{nmol} 1 / 2$ cystine/mg protein) and intermediate (3-6 nmol $1 / 2$ cystine $/ \mathrm{mg}$ protein) variants (8). Patient 2 had a leucocyte cystine content ( $2.85 \mathrm{nmol} 1 / 2$ cystine/mg protein) within the range for benign cystinosis; patient 1 had a leucocyte content of $4.4 \mathrm{nmol} 1 / 2$ cystine $/ \mathrm{mg}$ protein and a fibroblast level of $14.0 \mathrm{nmol} 1 / 2$ cystine/mg protein (Table 1 ).

It was possible, based on the different clinical manifestations, that the variant forms of cystinosis might result from a defect different from the well-recognized lysosomal cystine transport deficiency of infantile nephropathic cystinosis (4-7). We have now shown that, at least for two typical variant cystinosis patients, lysosomal cystine transport is defective (Tables 1 and 2), mitigating against the possibility that some process of lysosomal cystine catabolism is impaired in these variants.

When the velocity of cystine egress from leucocyte granular fractions was measured, cells of the benign variant resembled nephropathic cystinosis cells in showing virtually no loss of cystine. However, when the method of cystine counter-transport was employed, the benign cystinosis patient showed a significant residual cystine transport capacity (Table 2). This finding is consistent with the relatively low level of cystine storage in benign cystinosis. Parental values of cystine counter-transport, over $60 \%$ of normal, were also consistent with the presence of residual cystine carrying capacity in the patient, and support the autosomal recessive nature of inheritance originally proposed for benign cystinosis (15).

Recently, somatic cell fusion experiments have shown that benign and nephropathic cystinosis cells do not complement each other (25), suggesting that their mutations are allelic. While this may not hold for all combinations of benign and nephropathic cells, it supports our finding of decreased but measurable lysosomal cystine transport in benign cystinosis (Table 2), and suggests that the differences among cystinosis variants are in degree rather than in kind. We propose that there is a continuum of lysosomal cystine storage (and of lysosomal cystine carrier deficiency) superimposed on a background of diverse genetic predispositions and tissue susceptibilities. On the most severe end of this spectrum are children with a complete or nearly complete deficiency of cystine carrier whose renal cells are exquisitely sensitive to cystine storage and who succumb in the first few years of life. At the other end of the spectrum are patients with substantial residual cystine carrier activity, who store cystine to 10 to 20 times normal levels. This is enough to eventually form crystals in the cornea, conjunctiva, and bone marrow, but not in the kidneys. Similar to obligate heterozygotes for infantile nephropathic cystinosis, who store five to 10 times the normal amount of cystine (16) and have 30 to $70 \%$ of normal lysosomal cystine carrying capacity (24), these individuals are asymptomatic except for the occasional patient with photophobia (15). Intermediate in severity between these two extremes are adolescent cystinosis patients, whose slight reduction in cystine storage compared with infantile cystinosis patients suggests that they have a certain amount (perhaps not measurable) of residual lysosomal cystine carrying capacity. For these patients, the enormous variability in clinical course relates to the degree of residual activity combined with the differential susceptibility of tissues to cystine storage. It may even be that one individual, or one particular cell type, relies more on lysosomal proteolysis than another and, therefore, accumulates intralysosomal cystine more rapidly. Future determination of the molecular lesions in nephropathic, intermediate, and benign cystinosis will help confirm or deny this proposed explanation for the different clinical manifestation in these variants.

\section{REFERENCES}

1. Schulman JD 1973 Cystinosis. DHEW Publication no. (NIH) 72-249. Washington. D.C., NIH, pp $1-258$

2. Schneider JA, Schulman JD 1983 Cystinosis and the Fanconi syndrome. In: Stanbury JB, Wyngaarden JB, Fredrickson DS, Goldstein JL, Brown MS (eds) Metabolic Basis of Inherited Disease, 5th ed. McGraw Hill, New York, pp 1844-1866

3. Gahl WA 1986 Cystinosis coming of age. In: Advances in Pediatrics, Vol 33. Year Book Medical Publishers, Inc., Chicago, pp 95-126

4. Gahl WA, Tietze F, Bashan N, Steinherz R, Schulman JD 1982 Defective cystine exodus from isolated lysosome-rich fractions of cystinotic leucocytes. J Biol Chem 257:9570-9575

5. Gahl WA, Bashan N, Tietze F, Bernardini I, Schulman JD 1982 Cystine transport is defective in isolated leukocyte lysosomes from patients with cystinosis. Science 217:1263-1265

6. Jonas AJ, Smith ML, Schneider JA 1982 ATP-dependent lysosomal cystine efflux is defective in cystinosis. J Biol Chem 257:13185-13188

7. Gahl WA, Tietze F, Bashan N. Bernardini I, Raiford D, Schulman JD 1983 Characteristics of cystine counter-transport in normal and cystinotic lysosomal-rich leucocyte granular fractions. Biochem J 216:393-400

8. Goldman H, Scriver CR, Aaron K, Delvin E, Canlas Z 1971 Adolescent cystinosis: comparisons with infantile and adult forms. Pediatrics 47:979988

9. Hauglustaine D, Corbeel L, van Damme B, Serrus M, Michielsen P 1976 Glomerulonephritis in late-onset cystinosis. Report of two cases and review of the literature. Clin Nephrol 6:529-536

10. Dale RT, Gullapalli NR, Aquavella JV, Metz HS 1981 Adolescent cystinosis: a clinical and specular microscopic study of an unusual sibship. $\mathrm{Br} \mathrm{J}$ Ophthalmol 65:828-832

11. Manz. F, Harms E, Lutz, P, Waldherr R, Scharer K 1982 Adolescent cystinosis: renal function and morphology 138:354-357

12. Langman CB, Moore ES. Thoene JG, Schneider JA 1985 Renal failure in a sibship with late-onset cystinosis. J Pediatr 107:755-756

13. Cogan DG, Kuwabara T, Kinoshita J, Sheehan L, Merola L 1957 Cystinosis in an adult. JAMA 164:394-396

14. Cogan DG, Kuwabara T, Hurlbut CS, McMurray V 1958 Further observations on cystinosis in the adult. JAMA 166:1725-1726

15. Leitman PS, Frazier PD, Wong VG, Shotton D, Seegmiller JE 1966 Adult cystinosis-a benign disorder. Am J Med 40:511-517

16. Schneider JA, Wong V, Bradley K, Seegmiller JE 1968 Biochemical comparisons of the adult and childhood forms of cystinosis. N Engl J Med 279:12531257 
17. Brubaker RF, Wong VG, Schulman JD, Seegmiller JE, Kuwabara T 1970 Benign cystinosis: the clinical, biochemical and morphologic findings in a family with two affected siblings. Am J Med 49:546-550

18. Dodd MJ, Pusin SM. Green WR 1978 Adult cystinosis. A case report. Arch Ophthalmol 96:1054-1057

19. Tietze F, Rome LH. Butler JD, Harper GS, Gahl WA 1986 Impaired clearance of free cystine from lysosomal-enriched granular fractions of I-cell disease fibroblasts. Biochem J 237:9-15

20. Steinherz R. Tietze F. Raiford D. Gahl WA. Schulman JD 1982 Patterns of amino acid efflux from isolated normal and cystinotic human leucocyte lysosomes. J Biol Chem 257:6041-6049
21. Wilbrandt W, Rosenberg T 1961 The concept of carrier transport and its corollaries in pharmacology. Pharmacol Rev 13:109-183

22. Oshima RG, Willis RC, Furlong CE, Schneider JA 1974 Bindings assays for amino acids. J Biol Chem 249:6033-6039

23. Lowry OH, Rosenbrough NJ, Farr AL, Randall RJ 195I Protein measurement with the Folin phenol reagent. J Biol Chem 193:265-275

24. Gahl WA, Bashan N. Tietze F. Schulman JD 1984 Lysosomal cystine countertransport in heterozygotes for cystinosis. Am J Hum Genet 36:277-282

25. Smith ML, Pellet OL, Greene AA, Schneider JA 1986 Lack of complementation in somatic cell hybrids from fibroblasts of benign and nephropathic cystinotics. Pediatr Res 20:272A/711(abstr) 